\title{
Association between untreated carious lesions and asthma in adults at Rabat University Hospital, Morocco: a cross sectional study
}

\author{
Sanaa Chala ${ }^{1,3,6^{*}}$, Saloua Rouiffi ${ }^{4}$, Mouna Soualhi ${ }^{5}$, Jamal Eddine Bourkadi ${ }^{5}$, Redouane Abouqal ${ }^{2}$ \\ and Faïza Abdallaoui ${ }^{1,4}$
}

\begin{abstract}
Background: Depending on risk factors, cumulative risk of developing more dental caries by age has been reported. However, the association between dental caries and asthma is less studied among adults. The aims of this study were to evaluate the severity of untreated carious lesions in a population of asthmatic adults and to evaluate the mediation of socio-economic and oral health behaviour variables.
\end{abstract}

Methods: The study involved participants with diagnosed asthma $(N=100)$ and control $(N=100)$ subjects attending a tertiary hospital. Groups were matched by age and gender. Asthma was the exposure of interest. The outcome measure was the rate of carious lesions. Recorded variables included demographics, socio-economic status, tooth brushing habits and oral health status using WHO criteria. Poisson regression analysis examined the association between asthma and untreated dental caries.

Results: The adjusted model, after the inclusion of individuals' behaviours regarding oral health, social determinants and asthma, revealed a significant association between the number of untreated carious lesions and asthma $(\mathrm{PR}=1.23 ; 95 \% \mathrm{Cl} 1.23-1.58 ; p<0.001)$.

Conclusion: Patients with asthma showed a greater number of untreated carious lesions. Looking forward, better understanding of the association between asthma and oral health may require exploiting the interactions of behavioural, social determinant and biological factors.

Keywords: Asthma, Dental caries, Social determinants, Oral health behaviors

\section{Background}

Asthma is a common chronic condition that was still rising in prevalence in many countries during the last decades of the twentieth century but has stabilized in others $[1,2]$.

Like asthma, dental caries is a common public health condition particularly prevalent among high-risk individuals [3].

These two conditions result in both a burden on patient quality of life as well as tremendous socio-economic impact $[4,5]$.

\footnotetext{
*Correspondence: dr_chala@yahoo.fr

${ }^{6}$ Faculté de Medecine Dentaire de Rabat, BP: 6212. Rabat Instituts, Rabat, Morocco

Full list of author information is available at the end of the article
}

Over decades many papers have studied the association between asthma and oral health. Accumulating evidence suggests that asthmatic patients have an increased risk of dental caries [6, 7]. However, the pattern of association of asthma and dental caries has been more frequently studied among children.

Because adults normally are more prone to dental caries due to cumulative effects as they age, we conducted a retrospective cohort study of untreated dental caries severity among asthmatic adults. We hypothesized that those adults who have asthma, as compared with adults without asthma, would have an increased risk of having more tooth decay. Furthermore, we evaluated the mediation of socio-economic factors and oral health behaviours. 


\section{Methods}

To test the hypothesis that asthma is associated with high numbers of untreated carious lesions, cross-sectional analyses were performed.

Between October 2013 and May 2014, asthmatic patients aged 18 years or over attending Rabat University Hospital's Department of Allergy and Pulmonary Diseases were invited to participate in the study. Controls were patients treated at the Rabat Dental School during the same period. Informed consent was gained from the participants before inclusion. The study protocol was performed in accordance with ethics principles.

Criteria for inclusion were formulated to exclude adults treated for any other chronic diseases condition (e.g. cardio-vascular diseases, diabetes, etc.) or seeking the dental hospital for dental emergency needs. Cases and controls were matched by age and gender.

\section{Data collection}

Data were gathered through interview and oral examination.

Characteristics of the study population included:

- Demographic and socio-economic variables: age, gender, monthly household income (low, medium or high) and educational level (none, primary, secondary or university);

- Asthma status: yes or no;

- Oral health behaviours: information on frequency of tooth brushing (never, $\leq 2$ per day, $>2$ per day), regularity, age at beginning tooth brushing, the duration of tooth brushing and the brushing motion (appropriate or inappropriate); and,

- The nature of previous dental attendance, noted according to two categories: acute visit, aesthetic concern.

The intra-oral examinations, based on 28 teeth, used WHO criteria and included the decayed, missing and filled teeth (DMFT) index. Caries was recorded with tooth as the unit of measurement. Examinations were conducted using portable lamps and sterilized instruments.

Gingival health status was determined using the LöeSilness gingival index (GI), and plaque status using Silness-Löe plaque index (PI). The mean score for each patient was used to classify patients in regression analysis as follows:

- The GI was categorized: mild inflammation (0.1-1.0); moderate inflammation (1.1-1.9); and severe inflammation (2-3).

- The PI was categorized: good (0.1-1.0), fair (1.0-1.9) and poor (2-3).
Interrater reliability for carious lesions recording was performed on 20 participants using Cohen's kappa statistic. Interrater reliability of the carious lesion recording was 0.89 .

\section{Statistical analysis}

Data analysis was conducted using SPSS 13.0 software (Chicago, IL, USA). The data were presented as the mean \pm standard deviation (SD) for continuous variable with a normal distribution, and as median with interquartile range (IQR) for variables with skewed distribution. For categorical variables, data were presented as proportion.

Comparisons between categorical variables were determined using the Chi square test. Normally distributed continuous variables were analysed by Student's $t$ test. Comparisons between abnormally distributed variables were done by Mann-Whitney $U$ test.

We modelled the probability of having more carious lesions using Poisson regression analysis. Unadjusted and adjusted prevalence ratios (PR) and related 95\% confidence intervals of untreated carious lesions were calculated. Explanatory variables to be included on multivariable analysis were first identified in univariate analysis. The adjusted prevalence ratios were considered statistically significant when $p$ values were 0.05 or less.

\section{Results}

Two hundred adults were included during the study periods, of whom half were control. The mean age of participants was $36.3 \pm 15.1$ years and 152 (76\%) were female. Fifty-one (25.5\%) participants had no formal education.

Twenty-two (22\%) of the asthma patients had severe asthma. The median exposure time to asthma drugs was 9 (5-17) years. Oral corticosteroid (OCS) combined with inhaled salbutamol and inhaled corticosteroids were used by $43 \%$ of asthmatics. Twenty-three $(23 \%)$ of the asthmatic patients inhaled their asthma medication more than twice a day in all seasons.

The DMFT score of all patients was $16.1 \pm 7.6$. The prevalence of untreated carious lesions in the study population was $44.03 \%$. The median PI score for study subjects was 1.5 (1-2) and the median GI score was 1.25 (0.64-2).

Characteristics of patients according to asthma are shown in Table 1.

No significant difference between asthmatic and control groups was found with regard to oral hygiene practices.

Untreated carious lesions consisted of $48.09 \%$ of the DMFT among the asthmatic group.

The distribution of carious lesions profile according to tooth type was statistically different between asthma and non-asthma patients. 
Table 1 Demographic, socio-economic, oral health and clinical characteristics of studied groups according to their asthmatic status

\begin{tabular}{|c|c|c|c|}
\hline & \multicolumn{2}{|l|}{ Asthma } & \multirow[t]{2}{*}{$\mathbf{p}$} \\
\hline & Yes $(N=100)$ & No $(N=100)$ & \\
\hline Age (years), (mean \pm SD) & $36.4 \pm 15.2$ & $36.2 \pm 15.1$ & 0.94 \\
\hline Female gender, n (\%) & $76(76)$ & $76(76)$ & $>0.99$ \\
\hline Education level, $n(\%)$ & & & 0.24 \\
\hline Non & $31(31)$ & $20(20)$ & \\
\hline Primary & $18(18)$ & $18(18)$ & \\
\hline Secondary & $23(23)$ & $33(33)$ & \\
\hline University & $28(28)$ & $29(29)$ & \\
\hline Income, n(\%) & & & 0.13 \\
\hline Low & $39(39)$ & $28(28)$ & \\
\hline Medium & $34(34)$ & $47(47)$ & \\
\hline High & $27(27)$ & $25(25)$ & \\
\hline Age at beginning tooth brushing (years), [median (IQR)] & $12(7-20)$ & $10(7-19)$ & 0.54 \\
\hline Duration of brushing, (min), [median (IQR)] & $2(1-3)$ & $2(1-3)$ & 0.41 \\
\hline Inappropriate brushing motion, n(\%) & $48(48)$ & $51(51)$ & 0.61 \\
\hline $\mathrm{DMFT},($ mean $\pm \mathrm{SD})$ & $18.4 \pm 8.1$ & $13.8 \pm 6.4$ & $<0.001$ \\
\hline $\mathrm{DT},($ mean $\pm \mathrm{SD})$ & $8.8 \pm 4.6$ & $6.2 \pm 4.3$ & $<0.001$ \\
\hline MT, [median (IQR)] & $1(0-3)$ & $0(0-1)$ & $<0.001$ \\
\hline Proximal DT, [median (IQR)] & $4(1-7)$ & $1(0-3)$ & $<0.001$ \\
\hline Number of WSL at cervical mergins, [median (IQR)] & $0(0-4)$ & $0(0-1)$ & $<0.001$ \\
\hline $\mathrm{PI},[$ median $(\mathrm{IQR})]$ & $1.2(0.8-2)$ & $1.2(0.5-1.7)$ & $<0.001$ \\
\hline Gl, [median (IQR)] & $1.6(1-2.6)$ & $1.3(0.9-1.9)$ & 0.07 \\
\hline
\end{tabular}

IQR, interquartile range; $S D$, standard deviation; $M T$, number of missed teeth; $D T$, number of decayed untreated teeth; DMFT, number of decayed, missed and filled teeth; Gl, gingival index; PI, plaque index; WSL, white spot lesions; min, minutes; Proximal DT, number of proximal decayed untreated teeth

Results of Poisson regression analysis are shown in Table 2.

Univariate regression analysis showed that occupational status, low and medium education level, low and medium income, emergency dental attendance, never and 1 to 2 per-day frequency of tooth brushing, fair and poor plaque index, moderate and severe gingival inflammation, and asthma status were all identified as risk factors associated with a higher rate of dental caries.

Adjustment for these factors showed that occupational status, emergency dental attendance, frequency of tooth brushing and asthma status were associated with high rate of dental caries.

\section{Discussion}

The results of this analysis showed that the number of untreated carious lesions were higher among the asthma group. This result was observed in both univariate and multivariate analyses.

The present results are in line with those reported by Anjomshoaa et al. [8] and Johnston L, Vieira AR (2014). Both studies suggested the existence of an association between higher caries experience and asthma in adults $[8,9]$.
Yet there is little information available to document whether adults with asthma have worse oral health indicators than those without asthma. Most published studies were performed in children $[10,11]$ and in some cases conflicting results were found. Inconsistent results may be explained by differences in studied populations. Another explanation may be the chronic nature of dental caries. This explanation means that a period of time is required for the risk factors to contribute to the development of this disease. The exposure time to environmental factors that contribute to dental caries development in younger subjects may be shorter than that in adults. As such, the longer exposure time to asthma medications and behavioural factors means that the contribution of asthma and asthmatic medications to dental carious lesion development could be masked by the influence of other probable common risk factors.

The present study explored the association between asthma and the severity of untreated carious lesions. It is worth pointing out that most of previous studies used the DMFT index as indicator of dental caries; a claim-based definition of indicators in this study was to assess and 
Table 2 Uni and multi-variate analysis of factors associated with the number of untreated carious lesions

\begin{tabular}{|c|c|c|c|c|c|c|c|}
\hline & \multirow[t]{2}{*}{$\mathrm{DT}(\mathrm{m} \pm \mathrm{SD})$} & \multicolumn{3}{|c|}{ Univariate analysis } & \multicolumn{3}{|c|}{ Multivariate analysis } \\
\hline & & PR & $95 \% \mathrm{Cl}$ & $\mathrm{p}$ & PR & $95 \% \mathrm{Cl}$ & $\mathrm{p}$ \\
\hline Age, years & & 1.002 & $0.99-1.005$ & 0.36 & & & \\
\hline Female gender & $7.5 \pm 4.2$ & 1.03 & $0.91-1.16$ & 0.6 & & & \\
\hline \multicolumn{8}{|l|}{ Occupational status } \\
\hline Without & $8 \pm 3.9$ & 1.86 & $1.07-3.22$ & 0.02 & 1.97 & $1.07-3.60$ & 0.05 \\
\hline Student & $6.2 \pm 4.3$ & 1 & & & 1 & & \\
\hline Public employment & $6.7 \pm 5.3$ & 1.6 & $0.91-2.81$ & 0.09 & 2.00 & $1.09-3.66$ & 0.02 \\
\hline Private employment & $10.1 \pm 6$ & 2.33 & $1.33-4.08$ & 0.003 & 2.68 & $1.43-5$ & 0.002 \\
\hline \multicolumn{8}{|l|}{ Education level } \\
\hline No & $8.2 \pm 4.8$ & 1.22 & $1.08-1.37$ & 0.002 & 1.08 & $0.88-1.32$ & 0.42 \\
\hline Primary & $8.8 \pm 4.7$ & 1.34 & $1.15-1.49$ & $<0.001$ & 1.13 & $0.93-1.36$ & 0.21 \\
\hline Secondary and university & $6.7 \pm 4.5$ & 1 & & & 1 & & \\
\hline \multicolumn{8}{|l|}{ Income } \\
\hline Low & $9 \pm 4.3$ & 1.42 & $1.24-1.63$ & $<0.001$ & 1.12 & $0.86-1.46$ & 0.38 \\
\hline Medium & $7.1 \pm 4.4$ & 1.12 & $0.98-1.28$ & 0.08 & 1.30 & $1.03-1.65$ & 0.02 \\
\hline High & $6.3 \pm 4.8$ & 1 & & & 1 & & \\
\hline \multicolumn{8}{|c|}{ Nature of previous dental attendance } \\
\hline Acute visit & $9.2 \pm 4.8$ & 1.28 & $1.07-1.53$ & 0.005 & 1.37 & $1.09-1.72$ & 0.006 \\
\hline Aesthetic concern & $7.2 \pm 4.1$ & 1 & & & 1 & & \\
\hline \multicolumn{8}{|l|}{ Frequency of teeth bruising } \\
\hline Never & $7.9 \pm 4.6$ & 1.24 & $1.06-1.45$ & 0.006 & 1.26 & $1.08-1.47$ & 0.003 \\
\hline$\leq 2$ per day & $7.7 \pm 4.7$ & 1.17 & $1.008-1.37$ & 0.03 & 1.07 & $0.85-1.85$ & 0.53 \\
\hline$>2$ per day & $6.3 \pm 4.3$ & 1 & & & 1 & & \\
\hline Duration of teeth brushing & & 0.98 & $0.94-1.01$ & 0.32 & & & \\
\hline Age at beginning teeth brushing & & 1.01 & $1.005-1.01$ & $<0.001$ & 1.001 & $0.99-1.009$ & 0.84 \\
\hline Plaque index & & 1.28 & $1.20-1.36$ & $<0.001$ & 1.13 & $0.92-1.38$ & 0.22 \\
\hline Good & $5.6 \pm 4.4$ & 1 & & & 1 & & \\
\hline Fair & $7.1 \pm 4.5$ & 1.2 & $1.08-1.4$ & 0.002 & 1.17 & $0.95-1.6$ & 0.10 \\
\hline Poor & $9 \pm 4.5$ & 1.5 & $1.3-1.8$ & $<0.001$ & 1.23 & $0.96-1.42$ & 0.11 \\
\hline \multicolumn{8}{|l|}{ Gingival index } \\
\hline Mild & $6.4 \pm 4.4$ & 1 & & & 1 & & \\
\hline Moderate & $7.4 \pm 4.8$ & 1.16 & $1.19-1.55$ & $<0.001$ & 0.87 & $0.70-1.09$ & 0.24 \\
\hline Sever & $8.7 \pm 4.2$ & 1.3 & $1.02-1.3$ & 0.01 & 1.04 & $0.88-1.24$ & 0.59 \\
\hline \multicolumn{8}{|l|}{ Asthma } \\
\hline Yes & $8.8 \pm 4.6$ & 1.42 & $1.28-1.57$ & $<0.001$ & 1.39 & $1.23-1.58$ & $<0.001$ \\
\hline No & $6.2 \pm 4.3$ & 1 & & & 1 & & \\
\hline
\end{tabular}

$\mathrm{DT}$, number of decayed untreated teeth; 1 , reference category; $\mathrm{PR}$, prevalence ratio; $\mathrm{Cl}$, confidence interval; $\mathrm{m} \pm \mathrm{SD}, \mathrm{mean} \pm$ standard deviation

compare untreated carious lesions that may have resulted in healthcare resource use [12-14].

Dental caries is a multi-factorial chronic disease. It cannot develop without interaction with intermediary and environmental factors [15]. Factors like socio-economic background, oral health behaviours and eating habits may interact to explain the disease's prevalence. Socio-economic differences in oral health status have been reported in many studies [16, 17]. It is important to note that both studied groups have low educational background and social level. Another important specification of the studied group is that a large proportion of adults have unfavourable oral health behaviours. Socioeconomic status and oral health behaviours may confer additional disadvantages on carious lesion severity at tooth level [18]. These factors are strongly linked to dental caries and may mediate the link between asthma [19] and dental caries severity.

The mechanism of how asthma is associated with dental caries is still under exploration. Potential associations 
between asthma and the dental caries process cannot be solely attributed to one specific factor, but to a complex interaction among many factors including genetic factors, environmental exposures, nutrition, socio-economic status and access to health care. Asthmatic patients exposed to the same levels of environmental risk factors may not have the same susceptibility or resistance to dental caries.

A possible linkage between asthma and the dental caries process is genetic factors. Candidate gene categories to date include beta-defensin 1 [20-23] and matrix metalloproteinases [24, 25].

Asthma involves the immune system, and may disturb oral microbiota. Combined with anti-asthma medications $[26,27]$ this condition, may increase the risk of dental caries development at the individual level. As result, dysbiosis might increase the susceptibility to dental caries in asthmatic patients [26, 27].

Finally, depending on oral health behaviour, social status, genetic factors, and oral environment, the cumulative risk of developing more carious lesions may be more higher among asthmatic patients with genetic predisposition.

While several factors are associated with high risk of dental caries, exposure to some risk factors (i.e., limitations in oral health literacy, misconception about preventive measures, impairments in cognition) could be prevented.

Thus, community-based oral disease prevention and health promotion programs targeted to asthma patients should look beyond medications to cover differences in oral health behaviours, social factors, and other predisposing factors.

Asthma patients with high numbers of untreated carious lesions may require higher total health care costs and consequently a substantial economic cost to society.

Based on their current caries status or markers of disease, a high-risk strategy aiming to target asthma patients should be adopted. This simple public health intervention may lead to a significant reduction of the burden of dental caries and to its cost effectiveness among asthma adults.

The present study has some limitations that should be taken into account. The present findings involved a restricted group of patients and may underestimate the real burden among patients with limited resources and no access to care.

The socio-economic status was quite different between asthma and control groups. Thus, we caution that the present results may not reflect the mediation of socioeconomic status in carious lesion severity. Further research design taking into account matching asthma and control groups according to demographic and socio-economic background is needed.
Despite these limitations, the current report provides useful information about the factors that should be analysed when comparing groups regarding their exposure factors.

\section{Conclusions}

In cross-sectional analysis of present data, the presence of asthma was associated with a greater number of untreated carious lesions. Further studies are warranted to explore the role of common risk indicators.

\section{Abbreviations \\ PR: prevalence ratios; SD: standard deviation; Cl: confidence interval; DT: decayed untreated teeth; DMFT: decayed missed and treated teeth.}

\section{Authors' contributions}

SC was involved in the study design, performed the statistical analyses and drafted the manuscript. FA was involved in the study coordination. RA advised on the statistical analyses, the interpretation of the analyses and helped to draft the manuscript. SR, MS, JEB contributed to the preparation of the data. All authors read and approved the final manuscript.

\section{Author details}

${ }^{1}$ Research Team on Oral Ecosystem, Department of Endodontic and Restorative Dentistry, Faculty of Dentistry, Mohammed V University in Rabat, Rabat, Morocco. ${ }^{2}$ Laboratory of Biostatistics, Clinical and Epidemiological Research (LBRCE). Faculty of Medicine and Pharmacy, Mohammed V University in Rabat, Rabat, Morocco. ${ }^{3}$ Mohammed V Military Teaching Hospital, Rabat, Morocco.

${ }^{4}$ Faculty of Dental Medicine, Mohammed V University in Rabat, Rabat, Morocco. ${ }^{5}$ Department of Respiratory Diseases, Moulay Youssef Hospital, Rabat, Morocco Faculty of Medicine and Pharmacy, Mohammed V University in Rabat, Rabat, Morocco. ${ }^{6}$ Faculté de Medecine Dentaire de Rabat, BP: 6212. Rabat Instituts, Rabat, Morocco.

\section{Acknowledgements \\ We are grateful to all those who participated in this study}

\section{Competing interests}

The authors declare that they have no competing interests.

\section{Availability of data and materials}

Data are available upon request from the first and fifth authors

\section{Ethics approval and consent to participate}

The study protocol was performed in accordance with ethics principles. Approval of institutional review board of Mohammed V University in Rabat was obtained. We obtained informed consent from all participants. Analysis was conducted on anonymized data.

\section{Funding}

This study was funded by the research program supported by Mohammed $\mathrm{V}$ University Rabat and CNRST, Morocco.

\section{Publisher's Note}

Springer Nature remains neutral with regard to jurisdictional claims in published maps and institutional affiliations.

Received: 16 June 2016 Accepted: 17 June 2017

Published online: 26 June 2017

References

1. Eder W, Ege MJ, von Mutius E. The asthma epidemic. N Engl J Med. 2006;355:2226-35. 
2. Asher MI, Montefort S, Björksten B, Lai CK, Strachan DP, Weiland SK, et al. Worldwide time trends in the prevalence of symptoms of asthma, allergic rhinoconjunctivitis, and eczema in childhood: ISAAC Phases One and Three repeat multicountry cross-sectional surveys. Lancet. 2006;368:733-43

3. World Health Organization (WHO). Data and statistics. 2011. http://www. emro.who.int/data-and-statistics.html. Accessed 31 Jan 2016.

4. Chastek B, Korrer S, Nagar SP, Albers F, Yancey S, Ortega H, Forshag M, Dalal AA. Economic burden of illness among patients with severe asthma in a managed care setting. J Manag Care Spec Pharm. 2016;22:848-61.

5. Broadbent JM, Zeng J, Foster Page LA, Baker SR, Ramrakha S, Thomson WM. Oral health-related beliefs, behaviors, and outcomes through the life course. J Dent Res. 2016;95:808-13.

6. Vargas MH, Macedo-Sánchez F, Solís-Torres C, Rubio-Monteverde H, Furuya ME. Oral hygiene and dental status as factors related to asthma in high school and college students. J Asthma. 2015;52:376-81.

7. Stensson M, Wendt M, Koch G, Oldaeus G, Ramberg P, Birkhed D. Oral health in young adults with long-term, controlled asthma. Acta Odontol Scand. 2011;69:158-64.

8. Anjomshoaa I, Cooper ME, Vieira AR. Caries is associated with asthma and epilepsy. Eur J Dent. 2009;3:297-303.

9. Johnston L, Vieira AR. Caries experience and overall health status. Oral Health Prev Dent. 2014;12:163-70.

10. Meldrum AM, Thomson WM, Drummond BK, Sears MR. Is asthma a risk factor for dental caries? Finding from a cohort study. Caries Res. 2001;35:235-9.

11. Samec T, Amaechi BT, Battelino T, Krivec U, Jan J. Influence of anti-asthmatic medications on dental caries in children in Slovenia. Int J Paediatr Dent. 2013:23:188-96.

12. da Silva RP, Meneghim MC, Correr AB, Pereira AC, Ambrosano GM, Mialhe EL. Variations in caries diagnoses and treatment recommendations and their impacts on the costs of oral health care. Community Dent Health. 2012;29:25-8

13. Schwendicke F, Paris S, Stolpe M. Cost-effectiveness of caries excavations in different risk groups-a micro-simulation study. BMC Oral Health. 2014;15:153.

14. Decerle N, Nicolas E, Hennequin M. Chewing deficiencies in adults with multiple untreated carious lesions. Caries Res. 2013;47:330-7.

15. Preventive Medicine Compilation Committee. Preventive medicine. 3rd ed. Seoul: Gyechuk Munhwasa; 2004.
16. de Lima Vazquez F, Cortellazzi KL, Kaieda AK, Bulgareli JV, Mialhe FL, Ambrosano GM, da Silva Tagliaferro EP, Guerra LM, de Castro Meneghim M, Pereira AC. Individual and contextual factors related to dental caries in underprivileged Brazilian adolescents. BMC Oral Health. 2015;15:6.

17. Ayo-Yusuf IJ, Naidoo S. Social gradient in the cost of oral pain and related dental service utilisation among South African adults. BMC Oral Health. 2016;16:117.

18. Park JB, Han K, Park YG, Ko Y. Association between socioeconomic status and oral health behaviors: the 2008-2010 Korea national health and nutrition examination survey. Exp Ther Med. 2016;12:2657-64.

19. Centers for Disease Control and Prevention. Summary health statistics for US. National Health Interview Survey, Adults. 2012. http://www.cdc.gov/ nchs/data/series/sr_10/sr10_260.pdf. Accessed 14 Apr 2016.

20. Baines KJ, Wright TK, Simpson JL, McDonald VM, Wood LG, Parsons KS, Wark PA, Gibson PG. Airway $\beta$-defensin-1 protein is elevated in COPD and severe asthma. Mediat Inflamm. 2015;2015:407271.

21. Ozturk A, Famili P, Vieira AR. The antimicrobial peptide DEFB1 is associated with caries. J Dent Res. 2010;89:631-6.

22. Yildiz G, Ermis RB, Calapoglu NS, Celik EU, Türel GY. Gene-environment interactions in the etiology of dental caries. J Dent Res. 2016:95:74-9.

23. Levy H, Raby BA, Lake S, Tantisira KG, Kwiatkowski D, Lazarus R, Silverman EK, Richter B, Klimecki WT, Vercelli D, Martinez FD, Weiss ST. Association of defensin beta-1 gene polymorphisms with asthma. J Allergy Clin Immunol. 2005;115:252-8.

24. Grzela K, Litwiniuk M, Zagorska W, Grzela T. Airway remodeling in chronic obstructive pulmonary disease and asthma: the role of matrix metalloproteinase-9. Arch Immunol Ther Exp (Warsz). 2016;64:47-55.

25. Jain A, Bahuguna R. Role of matrix metalloproteinases in dental caries, pulp and periapical inflammation: an overview. J Oral Biol Craniofac Res. 2015;5:212-8.

26. Brigic A, Kobaslija S, Zukanovic A. Cariogenic potential of inhaled antiasthmatic drugs. Med Arch. 2015;69:247-50.

27. Chellaih P, Sivadas G, Chintu S, Vaishnavi Vedam VK, Arunachalam R, Sarsu M. Effect of anti-asthmatic drugs on dental health: a comparative study. J Pharm Bioallied Sci. 2016:8:S77-80.

\section{Submit your next manuscript to BioMed Central and we will help you at every step:}

- We accept pre-submission inquiries

- Our selector tool helps you to find the most relevant journal

- We provide round the clock customer support

- Convenient online submission

- Thorough peer review

- Inclusion in PubMed and all major indexing services

- Maximum visibility for your research

Submit your manuscript at www.biomedcentral.com/submit
BioMed Central 